DOI: $10.20472 /$ IAC.2018.040.017

\author{
FUAT ERDAL \\ Ibn Haldun University, Turkey \\ BULENT GULOGLU \\ Istanbul Technical University, Turkey \\ MURAT GUVEN \\ Istanbul Technical University, Turkey
}

\title{
REGIONAL DIFFERENCES IN CONSUMPTION PATTERNS IN TURKEY: AN ANALYSIS OF INCOME AND PRICE ELASTICITIES
}

\begin{abstract}
:
Studies on regional income and consumption disparities have always attracted the attentions of not only the economists but also of the social scientists in various fields. These differences are usually taken into account in designing regional development policies in many countries. There is a considerable amount of studies on regional income differences but studies on consumption differences are relatively limited. The purpose of the paper is to investigate if there are considerable differences in household consumption patterns across 26 regions of Turkey. We estimate income and price elasticites of demand for 12 groups of goods and services for the period from 2005 to 2013 by using the Geographically Weighted Panel Regression (GWPR) recently developed by Bruna and Yu (2013). The technique suggests that a set of global regression coefficients would not adequately take into account the underlying data generating process of the observed geographic dataset. For various reasons such as intrinsic varying mechanisms or potential misspecification, the relation between dependent and explanatory variables would differ from one location to other. GWR overcomes this shortcoming by estimating local coefficients along with global coefficients. The empirical results reveal that demand elasticities of price and income for shelter, furniture and beverages are similar between the east and the west regions; while demand elasticities for food, clothing, communication and education are varied across the regions.
\end{abstract}

\section{Keywords:}

Regional consumption disparities, geographically weighted panel regression, income elasticity, price elasticity

JEL Classification: R12, R58 